\title{
Investigation of the effect of hearing aid on hearing disability in elderly people with presbycusis
}

\section{İşitme cihazının presbiakuzili yaşlılarda işitme engelliliğine olan etkisinin araştırılması}

\author{
Süha Ertuğrul ${ }^{1}$, Emre Söylemez ${ }^{2}$
}

\begin{abstract}
Aim: To determine the effect of hearing aid on the level of hearing disability in elderly patients with presbycusis.

Methods: A hearing handicap inventory scale (HHI) was applied to 43 patients with presbycusis over the age of 65 years (mean age: $73.44 \pm 7.03$ years, range: $65-89$ years, male: 26 , female: 17 ) six months before using the hearing aid and 6 months after starting to use the hearing aid. HHI scores were compared before and after hearing aid.

Results: HHI scores $(22.51 \pm 14.81)$ after hearing aid use were significantly lower compared to HHI scores before hearing aid $(68.97 \pm 16.97)(\mathrm{p}=0.000)$. There was no significant difference between HHI score gains obtained after hearing aids according to gender $(\mathrm{p}=0.737)$. There was no significant difference between HH score gains obtained after hearing aids in patients with profound and severe hearing loss and the scores of the patients with moderate and moderate to severe hearing loss $(\mathrm{p}=0.521)$.

Conclusion: The hearing aid significantly reduces the level of auditory disability in elderly individuals.
\end{abstract}

Keywords: Hearing handicap inventory scale, hearing aid, hearing loss, presbycusis, sensorineural, elderly
1 Karabuk University, Faculty of Medicine, Department of Otorhinolaryngology, Karabuk, Turkey.

Karabuk University, Faculty of Medicine, Department of Audiology, Karabuk, Turkey.

Ethics Committee Approval: The study wass approved by the local ethical authority.

Etik Kurul Onayı: Çalışma lokal etik komite tarafindan onaylanmıştır.

Conflict of Interest: No conflict of interest was declared by the authors.

Çıkar Çatışması: Yazarlar çıkar çatışması bildirmemişlerdir.

Financial Disclosure: The authors declared that this study has received no financial support. Finansal Destek: Yazarlar bu çalışma için finansal destek almadıklarını beyan etmişlerdir.

Geliş Tarihi / Received: 11.12.2018 Kabul Tarihi / Accepted: 26.02.2019

Yayın Tarihi / Published: 15.03.2019

Sorumlu yazar / Corresponding author: Süha Ertuğrul

Adres/Address: Sirinevler mahallesi, Alpaslan caddesi, no:1, Postal code: 78200. Merkez, Karabuk, Turkey

e-posta: drsuhaertugrul@hotmail.com Tel/Phone: (+90) 03704125628

Copyright (C) ACEM 


\section{Introduction}

Sensorineural hearing loss (SNHL) may occur in many conditions such as maternal diseases and drugs used in the intrauterine period, genetic factors, premature birth, ototoxicity, exposure to high-intensity noise and aging. Having so many risk factors for SNHL makes it one of the most common health problems. SNHL can cause many problems such as tinnitus, anxiety, depression and decrease in quality of life in addition to communication problems [1].

Aging is continuous and irreversible changes emerge in tissues and organs with aging. The increase in average life expectancy and the increase in the elderly population also increased the number of individuals with hearing loss [2]. The elderly hearing loss is called presbycusis [3]. In presbycusis, hearing loss is bilateral, symmetrical, progressive and sensorineural. Hearing loss usually occurs at high frequencies and other frequencies get affected over time [4, 5]. Genetic factors and environmental conditions are effective in the emergence and progression of presbycusis [6]. In addition to presbycusis, elderly people may have conductive and mixed type hearing loss [3]. In this case, the treatment modalities of hearing loss may also change. There is no medical or surgical treatment of presbycusis. The only treatment is a suitable hearing aid (HA). The use of hearing aids in individuals with presbycusis in the early stage may stop the progression of SNHL. In addition, early use of hearing aids can also prevent cognitive impairment and psychological problems [7]. Approximately, $40 \%$ of the individuals, on whom HA applied, stop using HA due to psychological problems or cognitive impairment by thinking that they do not benefit from it $[8,9]$. Therefore, it is recommended that patients with presbycusis be diagnosed in the early stage and start using hearing aid early. However, there is resistance and prejudice against the early use of hearing aids in our country. For this reason, many patients in our country prefer to use hearing aids when they have a severe hearing loss.

In this study, we aimed to determine whether the hearing aid had an effect on hearing disability level in the elderly patients with presbycusis.

\section{Material and methods}

\section{Patient selection}

In this prospective study, patients admitted to the otorhinolaryngology outpatient clinic with complaints of hearing loss between February 2018 and April 2018 were evaluated. After the detailed history of all patients, ear-nose-throat examinations were performed. Patients aged 65 years and over, whose otoscopy examination was evaluated as normal, who had no acute or chronic infectious disease, have not undergone any ear surgery, have never previously used hearing aids, were diagnosed with presbycusis and in who have SNHL as bilateral $35 \mathrm{~dB}$ or more, were included in the study. The patients who have previously used hearing aids, patients who had ear surgery, patients under 65 years old, patients with unilateral SNHL, patients with conductive or mixed type hearing loss were excluded from the study. Patients who did not have Tip A tympanograms were also excluded from the study. Sixty patients who met the inclusion and exclusion criteria were recommended a digital programmable postauricular hearing aid. It has been planned to apply hearing handicap inventory scale (HHI) (Table 1) to the patients before the hearing aid and six months after the patient started to use the device. Although hearing aid was recommended, patients who did not use hearing aids and patients who did not come for follow-up at the sixth month were excluded from the study. As a result, the study was completed with 43 patients.

The working protocol was prepared in accordance with the principles set out in the Helsinki Declaration. An approval was received from the clinical research ethics committee within our university (2018-6/8). Written informed consent was obtained from all patients.

\begin{tabular}{llll} 
Table 1. Hearing Handicap Inventory Scale. & & \\
\hline Question & Yes & $\begin{array}{l}\text { Someti } \\
\text { mes }\end{array}$ & $\begin{array}{l}\text { N } \\
\text { o }\end{array}$
\end{tabular}

1S Does your difficulty in hearing bring you problems when using the telephone?

2E Does a hearing problem cause you to feel embarrassed when meeting new people?

3S Does a hearing problem cause you to avoid groups of people?

4E Does a hearing problem make you irritable?

$5 \mathrm{E}$ Does a hearing problem cause you to feel frustrated when talking to members of your family?

6S Does a hearing problem cause you difficulty when attending a party?

7S Does a hearing problem cause you to feel frustrated when talking to co-workers, clients, or customers?

8E Does a hearing problem cause you difficulty when going to the cinema or theater?

9S Do you feel handicapped by a hearing problem?

$10 \mathrm{E}$ Does a hearing problem cause you difficulty when visiting friends, relatives, or neighbors?

$11 \mathrm{~S}$ Does a hearing problem cause you tdifficulty to listen/understand co-workers?

12E Does a hearing problem cause you to be nervous?

13S Does a hearing problem cause you to visit friends, relatives, or neighbors less often than you would like?

14E Does a hearing problem cause you to have arguments with family members?

15S Does a hearing problem cause you difficulty when listening to TV or radio Does a hearing problem cause you difficulty when listening to TV or radio?

$16 \mathrm{~S}$ Does a hearing problem cause you to go shopping less often than you would like?

17E Does any problem or difficulty with your hearing upset you at all?

18E Does a hearing problem cause you to want to be by yourself?

19S Does a hearing problem cause you to talk to family members less often than you would like?

20E Do you feel that any difficulty with your hearing limits or hampers your personal or social life?

21S Does a hearing problem cause you difficulty when in a restaurant with relatives or friends?

22E Does a hearing problem cause you to feel depressed?

23S Does a hearing problem cause you to listen to TV or radio less often than you would like?

24E Does a hearing problem cause you to feel uncomfortable when talking to friends?

$25 \mathrm{E}$ Does a hearing problem cause you to feel left out when you are with a group of people?

Total score:_ E Score:_ S score:

\section{Assessment of hearing}

All audiological tests were performed by the authors. Clinical audiometry device (AC 40, DK-500; Interacoustics, Middelfart, Denmark) was used to evaluate the hearing levels. Pure-tone air conduction hearing threshold values of patients were measured at frequencies of $125 \mathrm{~Hz}, 250 \mathrm{~Hz}, 500 \mathrm{~Hz}, 1000$ $\mathrm{Hz}, 2000 \mathrm{~Hz}, 4000 \mathrm{~Hz}, 6000 \mathrm{~Hz}$, and $8000 \mathrm{~Hz}$. Pure-tone bone conduction hearing threshold values of the patients were measured at frequencies of $500 \mathrm{~Hz}, 1000 \mathrm{~Hz}, 2000 \mathrm{~Hz}, 4000 \mathrm{~Hz}$. Speech recognition threshold (SRT) and speech recognition 
score (SRS) tests were performed. The pure tone average (PTA) was calculated by taking the average of hearing thresholds at frequencies of $500 \mathrm{~Hz}, 1000 \mathrm{~Hz}, 2000 \mathrm{~Hz}$, and $4000 \mathrm{~Hz}$. According to PTA results, the degree of hearing loss was considered to be mild ( $26 \mathrm{~dB}$ to $40 \mathrm{~dB})$, moderate $(41 \mathrm{~dB}$ to 55 $\mathrm{dB})$, moderate to severe $(56 \mathrm{~dB}$ to $70 \mathrm{~dB})$, severe $(71 \mathrm{~dB}$ to 90 $\mathrm{dB})$ and profound (91 dB and above). Tympanometry measurement was performed with the impedance audiometer (AZ 26; Interacoustics, Middelfart, Denmark) in $226 \mathrm{~Hz}$ octave band by using $86 \mathrm{~dB}$ SPL probe tone stimulation. Type A tympanogram was accepted as normal.

\section{Hearing Handicap Inventory Scale}

HHI consists of 25 questions. 12 of these questions contain information about the social situation and 13 of them contain about emotional status [10]. Every question includes three options as yes ( 4 points), sometimes ( 2 points) and no (0 points) and the total score is evaluated over 100 points. Total score; 0-16 points were considered as no handicap, $18-42$ points as a mild to moderate handicap and $44-100$ points as a significant handicap.

Social, emotional and total HHI scores were compared before the use of hearing aid and at the sixth month of use. HHI score gains obtained by patients after HA were compared according to gender. HHI score gains were compared between the patients with severe and profound hearing loss and the patients with moderate and moderate to severe hearing loss.

\section{Statistical Analysis}

As a statistical method, SPSS version 21 (SPSS software, SPSS Inc., Chicago, IL, USA) was used. Percent, mean, standard deviation (SD), median, minimum and maximum values were presented for descriptive statistics. A Paired t-test was used to evaluate the difference between HHI scores before the using HA and the HHI scores that were applied at the sixth month of the HA use. Student's T-test was used to compare the HHI score gains obtained by the patients after HA according to the test. Student's T-test was used to compare HHI score gains that severe and profound hearing loss patients and patients with moderate and moderate to severe hearing loss obtained after HA. $P$ value as $<0.05$ was considered statistically significant.

\section{Results}

Of the 43 patients included in the study, 17 (39.5\%) were female and $26(60.5 \%)$ were male. The mean age was 73.44 \pm 7.03 years (range, 65-89 years). HA was provided to the left ear of 23 patients $(53.4 \%)$ and the right ear of 20 patients $(56.6 \%)$. The results of PTA, SRT, and SRS before using the hearing aids on the right and left ears of the patients are given in Table 2. Fourteen of the patients $(32.5 \%)$ had moderate hearing loss, $16(37.2 \%)$ had moderate to severe, $11(25.5 \%)$ were severe and two $(4.6 \%)$ had profound hearing loss. Forty-one patients (95.3\%) had a significant handicap and two patients $(4.7 \%)$ had mild to moderate handicap according to HHI scores before using HA. According to the HHI scores applied at the six months after the use of HA, the auditory disability was completely disappeared in 17 patients (39.5\%), 22 patients (51.2\%) had a mild to moderate handicap and four patients $(9.3 \%)$ had a significant handicap. After using hearing aids, the emotional, social and total HHI scores of women and men were significantly decreased $(\mathrm{p}=0.001)$ (Table 3$)$. There was no significant difference between the gains in HHI score of the patients according to gender $(\mathrm{p}=0.737)$. There was no significant difference between the HHI score gains obtained after HA in patients with the profound and severe hearing loss and the scores of the patients with moderate and moderate to severe hearing loss $(\mathrm{p}=0.521)$.

Table 2. Pure tone averages, speech receiving threshold values and speech discrimination rates of the patients before use of the hearing aid in the right and the left ear.

\begin{tabular}{lcccc} 
& \multicolumn{2}{c}{ Right ear } & \multicolumn{2}{c}{ Left ear } \\
\cline { 2 - 5 } Variable & Mean \pm SD & $\begin{array}{l}\text { Min- } \\
\text { Max }\end{array}$ & Mean \pm SD & $\begin{array}{c}\text { Min- } \\
\text { Max }\end{array}$ \\
\hline PTA (dB nHL) & $64.65 \pm 17.14$ & $30-113$ & $65.58 \pm 15.92$ & $45-112$ \\
SRT (dB nHL) & $61.04 \pm 16.53$ & $30-100$ & $60.69 \pm 14.62$ & $40-100$ \\
SRS $(\%)$ & $59.58 \pm 23.59$ & $0-96$ & $58.55 \pm 24.84$ & $0-96$ \\
\hline PTA: pure tone averages, SRT: speech & recognition threshold, SRS: speech \\
recognition scores, SD: standart deviation, Min: minimum, Max: maximum.
\end{tabular}

Table 3. HHI scores of the patients before using the hearing aid and 6 months after.

\begin{tabular}{llllll} 
& \multicolumn{2}{c}{ Before HA } & \multicolumn{2}{c}{ After HA } & \\
\cline { 2 - 5 } Variable & Mean \pm SD & $\begin{array}{l}\text { Min- } \\
\text { Max }\end{array}$ & Mean \pm SD & $\begin{array}{l}\text { Min- } \\
\text { Max }\end{array}$ & P \\
\hline Total HHI Score & $68.97 \pm 16.97$ & $20-96$ & $22.51 \pm 14.81$ & $0-60$ & 0.001 \\
$\quad$ Male & $69.07 \pm 18.26$ & $20-96$ & $23.00 \pm 16.33$ & $0-60$ & \\
$\quad$ Female & $68.82 \pm 15.34$ & $38-88$ & $21.76 \pm 12.56$ & $6-52$ & \\
Total emotional & $33.90 \pm 12.54$ & $12-54$ & $10.72 \pm 6.94$ & $0-24$ & 0.001 \\
$\quad$ score & & & & & \\
Male & $34.00 \pm 9.74$ & $12-48$ & $11.07 \pm 8.06$ & $0-24$ & \\
Female & $33.76 \pm 11.02$ & $18-54$ & $10.23 \pm 4.94$ & $4-20$ & \\
Total social score & $35.06 \pm 9.32$ & $8-52$ & $11.76 \pm 8.92$ & $0-40$ & 0.001 \\
$\quad$ Male & $35.07 \pm 10.26$ & $8-52$ & $11.92 \pm 9.55$ & $0-40$ & \\
Female & $35.05 \pm 7.97$ & $20-44$ & $11.52 \pm 8.14$ & $0-32$ & \\
\hline
\end{tabular}

HHI: hearing handicap inventory scale, HA: hearing aid, SD: standart deviation, Min: minimum, Max: maximum.

\section{Discussion}

As it affects the whole body, aging also affects the Corti organ, the auditory nerve, and the auditory cortex. Cell aging in the auditory pathway leads to SNHL, which is defined as presbycusis. Presbycusis causes difficulty in understanding the conversations, decreasing verbal communication skills, negatively affecting social lives and decreasing quality of life [3, $6,11]$. There are many questionnaires evaluating health quality and satisfaction level of patients using hearing aids. Glasgow Hearing Aid Benefit Profile, The Speech, Spatial and Qualities of Hearing Scale, Hearing Aid Performance Questionnaire, Satisfaction with Amplification in Daily Life, Abbreviated Profile of Hearing Aid Benefit and International Outcome Inventory for Hearing Aids are some of those. In our study, we wanted to investigate the effect of hearing aid on auditory disability rather than its effect on patient satisfaction. For this reason, we chose the HHI scale, which contains easy to understandable questions for the Turkish people.

In our study, we have found that the use of HA significantly decreases the level of social and emotional disability in elderly individuals with presbycusis. However, there was no difference in terms of the benefit that men and women with presbycusis gained from HA. In some studies, it has been reported that there is no relationship between gender and hearing aid satisfaction [12-15]. According to the studies evaluating the relationship between age and hearing aid satisfaction, different results are obtained in the literature. Many studies have found that age does not affect hearing aid satisfaction [12, 15-17]. In some studies, young elderly people were found to be more satisfied with hearing aids than older ones [18, 19]. Korkmaz et al. [20] found that the satisfaction of hearing devices decreased in advanced ages. They also stated that there is an overall 
decrease in general life satisfaction due to activity limitations and increased systemic problems with advanced ages [20].

In the literature, there are many studies suggesting that the HA improves quality of life and reduces hearing disability rates $[3,21]$. In the study conducted on Iranian people, Lotfi et al. [3] reported that HA improved quality of life. In their study, they applied HHI scale before and 3 months after the use of HA and found that the total HHI score decreased from 65 to 22 . Vuorialho et al. [21], in their study in Finland, applied the HHI scale before the use of the hearing aid and 6 months after the use of the device and found that HHI scores decreased from 28.7 to 12.7. In our study, we also performed HHI 6 months after the patients started to use HA for the realization of auditory adaptation similar to Vuorialho et al. [21]. In our study, HHI scores performed before HA were high as in the study Lotfi et al. [3] conducted. However, in the study conducted in Finland [21], the pre-HA HHI scores were significantly lower compared to the scores both in our study and the study by Lotfi et al. [3] conducted. The reasons for such a difference between societies according to HHI scores are due to the socio-cultural differences and economic reasons. These results may be indicative of the fact that patients in advanced western countries, such as Finland, have begun to use hearing aids without increasing the level of hearing disability.

In some studies, it has been reported that hearing loss does not only affect individuals with presbycusis, but also adversely affects families and close friends [6, 21]. In our study question, \#14 (Does your hearing loss cause you to argue with your family members?) was one of the questions receiving the highest scoring (not shown data). Elderly individuals with having arguments with the families or close environment can cause them to be more withdrawn and lead to social isolation. In addition, one of the biggest problems experienced by the patients in our study was to listen to the radio or television which was questioned on the HHI scale by \#15 question (not shown data). Elderly people may be more directed towards television and radio, but because they do not fully understand the television and radio, dissatisfaction and unhappiness may be increasing.

$\mathrm{HA}$ is an important and effective rehabilitation method for moderate and moderate to severe hearing loss, and it can be recommended as a preventive method for patients with mild hearing loss [22, 23]. It has been stated that the fitting setting of the hearing aid changes the use and effect of the device [21]. Magni et al. [24] investigated the effectiveness of analog and digital hearing aids. They stated that devices with different features had differed from the benefits provided to the individuals, however, the patients benefited from both devices. In our study, all individuals were using digital and postauricular programmable HA. In addition, although HA is an effective rehabilitation method for moderate and moderate to severe hearing loss, in our study, it was found that individuals with severe and profound hearing loss also benefited from HA. With the developing HA technology and HA fitting experience, we think that hearing aids may be recommended for more severe and profound hearing loss in the future.

The limitations of our study were low patient population and lack of speech recognition scores with hearing aids.

As a conclusion, $\mathrm{HA}$ is an effective treatment for the rehabilitation of elderly individuals with presbycusis. HA reduces auditory disability in patients with moderate, moderate to severe, severe and profound hearing loss and significantly increase these individuals' social and emotional life quality emerging due to hearing loss.

\section{References}

1. Dalton DS, Cruickshanks KJ, Klein BE, Klein R, Wiley TL, Nondahl DM. The impact of hearing loss on quality of life in older adults. Gerontologist. 2003;43:661-8

2. Byun YS, Kim SS, Park SH, Park EB, Kim HJ, Kim SH, et al. Characteristics of patients with hearing aids according to the degree and pattern of hearing loss. J Audiol Otol. 2016;20:146-52.

3. Lotfi Y, Mehrkian S, Moossavi A, Faghih-Zadeh S. Quality of life improvement in hearing-impaired elderly people after wearing a hearing aid, Arch Iran Med. 2009;12:365-70.

4. Crispim KGM, Ferreira AP. Prevalence of self-reported hearing loss and associated risk factors among the elderly in Manaus: a population-based study. Rev CEFAC. 2015; 17:1946-56.

5. Paiva KM, Cesar CL, Alves MC, Barros MB, Carandina L, Goldbaum M. Aging and self-reported hearing loss: a population-based study. Cad Saude Publica. 2011;27:1292-300.

6. Fischer N, Weber B, Riechelmann H. Presbycusis - age related hearing loss. Laryngorhinootologie. 2016;95:497-510.

7. Carniel CZ, Sousa JCF, Silva CDD, Fortunato-Queiroz CAU, Hyppolito MÂ, Santos PLD. Implications of using the hearing aids on quality of life of elderly. Codas. 2017;29:e20160241.

8. Smeeth L, Fletcher AE, Ng ES, Stirling S, Nunes M, Breeze E, et al. Reduced hearing, ownership, and use of hearing aids in elderly people in the UK - the MRC trial of the assessment and management of older people in the community: a cross-sectional survey. Lancet. 2002;359:1466-70.

9. Rutman D, Boisseau B. Acquired hearing loss: social and psychological issues and adjustment processes. Int J Rehabil Res. 1995;18:313-23.

10. Weinstein BE, Ventry IM. Audiometric correlations of the Hearing Handicap Inventory for the elderly. J Speech Hear Disord. 1983;48:37984.

11. Veras RP, Mattos LC. Audiology and aging: literature review and current. Braz J Otorhinolaryngol. 2007;73:122-8.

12. Uriarte M, Denzin L, Dunstan A, Sellars J, Hickson L. Measuring hearing aid outcomes using the Satisfaction with Amplification in Daily Life (SADL) questionnaire: Australian data. J Am Acad Audiol. 2015;16:383-402.

13. Wong LL, Hickson L, McPherson B. Hearing aid satisfaction: what does research from the past 20 years say? Trends Amplif. 2003;7:117-61.

14. Knudsen LV, Oberg M, Nielsen C, Naylor G, Kramer SE. Factors influencing help seeking, hearing aid uptake, hearing aid use and satisfaction with hearing aids: a review of the literature. Trends Amplif. 2010;14:127-54.

15. Jerram JCK, Purdy SC. Technology, expectations, and adjustment to hearing loss: predictors of hearing aid outcome. J Am Acad Audiol. 2001;12:64-79.

16. Chang WH, Tseng HC, Chao TK, Hsu CJ, Liu TC. Measurement of hearing aid outcome in the elderly: comparison between young and old elderly. Otolaryngol Head Neck Surg. 2008;138:730-34.

17. Brooks DN, Hallam RS. Attitudes to hearing difficulty and hearing aids and the outcome of audiological rehabilitation. $\mathrm{Br} \mathrm{J}$ Audiol. 1998;32:217-26.

18. Mulrow CD, Tuley MR, Aguilar C. Correlates of successful hearing aid use in older adults. Ear Hear.1992; 13:108-13.

19. Hosford-Dunn H, Halpern J. Clinical application of the SADL scale in private practice II: predictive validity of fitting variables. Satisfaction with amplification in daily life. J Am Acad Audiol. 2001;12:15-36.

20. Korkmaz MH, Bayır O, Er S, Isık E, Saylam G, Tatar EC, et al Satisfaction and compliance of adult patients using hearing aid and evaluation of factors affecting them. Eur Arch Otorhinolaryngol. 2016;273:3723-32.

21. Vuorialho A, Karinen P, Sorri M. Effect of hearing aids on hearing disability and quality of life in the elderly. Int J Audiol. 2006;45:400-5.

22. Choi J, Chung WH. Age-related hearing loss and the effects of hearing aids. J Korean Med Assoc. 2011;54:918-24.

23. Chang YS, Choi J, Park GY, Youm HY, Byun HY, Cho YS. Evaluation of satisfaction with hearing aids using a questionnaire based on markeTrak survey. Korean J Otorhinolaryngol-Head Neck Surg. 2014;57:304-13.

24. Magni C, Freiberger F, Tonn K. Evaluation of satisfaction measures of analog and digital hearing aid users. Braz $\mathrm{J}$ Otorhinolaryngol. 2005;71:650-7. 